\title{
BRACHIAL PLEXUS INJURIES
}

ROLFE BIRCH

\author{
From the Royal National Orthopaedic Hospital, Stanmore, England
}

Injuries to the brachial plexus are common and are the most severe of all lesions of peripheral nerves, but the last 25 years have seen considerable advances in treatment. Much of this improvement followed the restatement of surgical principles regarding the treatment of wounds, and the application of methods of diagnosis and techniques of nerve repair which had been established much earlier. In 1954 a Special Report of the Medical Research Council commenting on 170 open war-time injuries concluded that "with the possible exception of lesions of the upper trunk, operative repair is valueless". This view was supported at the Paris SICOT meeting in the mid 1960s and was probably incorrect then. It is certainly incorrect now.

History. The Iliad contains descriptions both of open wounds and closed injuries of the brachial plexus. Flaubert (1827) described the findings at necropsy in a case of attempted late closed reduction of dislocation of the shoulder with fatal outcome. He found rupture of the subclavian artery, avulsion of spinal nerves from the spinal cord and haematoma within the spinal canal. The patient showed signs of a Brown-Séquard lesion before death. Frazier and Skillern (1911) confirmed by hemilaminectomy that spinal nerves had been torn directly from the spinal cord in a patient who gave an eloquent description of pain wholly characteristic of intradural injury. Thorburn (1900) performed the first repair of a traction rupture in 1896 and a number of other reports followed this. Surgical repair lost favour, however, because of difficulties in diagnosis and in measuring outcome, and because there were deaths.

Inevitably, warfare stimulated study. The First World War led to seminal work on the effects of ischaemia and aneurysm on peripheral nerves, and the papers of the great French surgeon-anatomists on the exposure of deep-seated blood vessels, summarised by Fiolle and Delmas (1921), are still influential. After the Second World War, the contributions of those brought together by the British Medical Research Council laid the foundation of much modern work. Brooks (1955) established the place of nerve grafting; Seddon (1963) described the first case of active elbow flexion after intercostal transfer; Strange (1947) developed

R. Birch, FRCS, Consultant Orthopaedic Surgeon

Royal National Orthopaedic Hospital, Brockley Hill, Stanmore, London HA7 4LP, UK.

Updated text and illustrations, printed with the permission of EFORT. The original article appears in European Instructional Course Lectures Vol. 2, 1995. the vascularised nerve graft on a pedicle; and Young and Medawar (1940) introduced fibrin-clot glue. Later wars helped to stimulate the development of reliable techniques for repair of blood vessels.

Much work was done in London at the Royal National Orthopaedic Hospital and St Mary's Hospital on the diagnosis and treatment of the closed lesions. Bonney introduced simple clinical tests to distinguish between pre- and postganglionic injury, an advance of fundamental importance (Bonney 1954; Bonney and Gilliatt 1958). Electrophysiological examination was refined and extended by Landi et al (1980) who demonstrated the value of cortically evoked potentials.

From other centres, Celli and Rovesta (1987) combined EMG examination of paravertebral muscles with pre- and intraoperative sensory evoked potentials, and Sugioka and Nagano (1989) compared pre- and intraoperative electrophysiology with the findings at operation. The value of myelography was established in the 1960s (Yeoman 1958; Davies, Sutton and Bligh 1966), but Marshall and de Silva (1986) showed that CT with contrast enhancement was more accurate.

Despite these developments, the few surgeons persisting with the repair of closed lesions became disappointed with their results, but interest was rekindled by the work of Narakas in Lausanne and Millesi and his colleagues in Vienna in the early 1960s. Their work stimulated others; and there is a useful summary in the collection of essays published by the Groupe d'Étude de la Main in 1989. It is now time to take stock of the considerable experience which has been collected since 1970 (Tables I and II).

\section{PRINCIPLES OF TREATMENT}

The fundamental aim is to establish an accurate diagnosis and then to attempt to improve the prognosis. This should be done as soon as possible and requires urgent restoration of circulation, stabilisation of associated fractures, adequate exposure of the lesions with intraoperative physiological monitoring and early nerve repair. Some $15 \%$ of patients with closed traction lesions of the brachial plexus also sustain severe and potentially life-threatening injuries to the head, chest, or viscera; fractures of long bones are found in over $50 \%$. These must take priority. Rupture of the subclavian-axillary artery occurs in $10 \%$ of supraclavicular and in over $20 \%$ of infraclavicular lesions. The incidence of vascular injury is higher in open wounds.

The prognosis for limb function is determined by urgent 
Table I. Operations for injuries of the brachial plexus 1976 to 1996, showing the incidence of open and of vascular injuries

\begin{tabular}{|c|c|c|c|c|}
\hline & Total & Open & Vascular & $\begin{array}{l}\text { Urgent } \\
\text { amputation }\end{array}$ \\
\hline $\begin{array}{l}\text { Supraclavicular } \\
\text { Complete avulsion (C4) C5 to T1 } \\
\text { No repair }\end{array}$ & 148 & 6 & 48 & 8 \\
\hline $\begin{array}{l}\text { Incomplete or recovering lesions } \\
\text { No repair }\end{array}$ & 262 & 24 & 20 & 1 \\
\hline Repairs in complete or partial lesions & 687 & 32 & 42 & 2 \\
\hline Repairs by vascularised ulnar nerve graft & 65 & 14 & 5 & 0 \\
\hline Total & 1162 & 76 & 115 & 11 \\
\hline $\begin{array}{l}\text { Infraclavicular } \\
\quad \text { Involving suprascapular and circumflex nerves }\end{array}$ & 126 & 6 & 6 & 0 \\
\hline Caused by shoulder dislocation: no nerve rupture & 26 & 0 & 2 & 0 \\
\hline $\begin{array}{l}\text { Caused by shoulder dislocation, with vascular } \\
\text { injury but no nerve rupture, in older patients }\end{array}$ & 8 & 0 & 8 & 0 \\
\hline $\begin{array}{l}\text { Multiple ruptures of nerves (the true } \\
\text { infraclavicular lesion) }\end{array}$ & 282 & 54 & 62 & 3 \\
\hline Total & 442 & 60 & 78 & 3 \\
\hline Penetrating missile injury & 51 & & & \\
\hline
\end{tabular}

Table II. Patterns of injury in 300 consecutive closed supraclavicular lesions having operations from 1989 to 1992

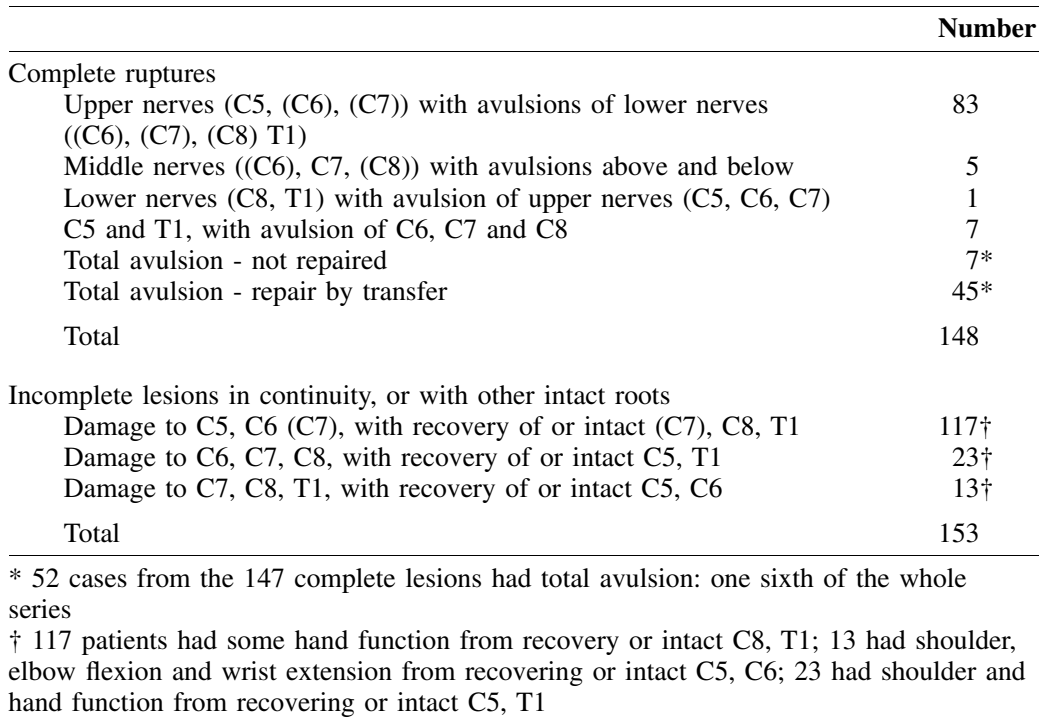

and successful repair of the vessels. DeBakey and Simeone (1955) reviewed Second World War experience and found that gangrene followed ligation of the subclavian artery in over $25 \%$ of cases; after ligation of the axillary artery gangrene occurred in just under $50 \%$. These were war wounds; injuries in civilian practice are less severe, but failure to restore prompt circulation is almost always followed by ischaemic fibrosis or worse. Bonney (1959) emphasised that an intradural injury of the brachial plexus is an injury of the central nervous system and that BrownSéquard syndrome will occur in at least $10 \%$ of patients with complete lesions. Injury to the spinal cord at another level is found in $2 \%$ to $3 \%$ of all cases.

Investigations. Thorough and repeated general clinical examination is necessary to detect progressive injuries to the head, the chest and abdomen. When there is clinical suspicion of damage to the arch of the aorta arteriography is essential; it must be remembered that a knife or missile does not respect tissue planes. We have seen an aneurysm of the axillary artery after a missile injury to the opposite arm and an arteriovenous fistula in the posterior triangle of the neck after a missile entered the arm and exited below the spine of the scapula.

Angiography, however, is not always necessary before urgent surgery. Frank bleeding from an open wound or an expanding swelling with or without a bruit indicates an arterial injury. A loud bruit suggests an arteriovenous fistula. The clinical diagnosis of rupture of the axillary artery in 
a high-energy closed infraclavicular lesion is usually straightforward: the posterior triangle of the neck is not swollen, the subclavian pulse can be felt, there is an enlarging swelling below the clavicle and there is no brachial pulse. In such a case angiography would cause unnecessary delay.

Diagnosis of the neural injury. The essential element in diagnosis is the distinction between pre- and postganglionic lesions. In preganglionic rupture, the afferent nerve fibres with cell bodies in the dorsal root ganglion do not degenerate. Only efferent fibres to skeletal or smooth muscle undergo Wallerian degeneration. It is now of more than academic interest that a preganglionic or intradural lesion is diagnosed more accurately as either a rupture of the rootlet peripheral to the central peripheral transmission zone (Berthold, Carlstedt and Corneliuson 1993) or a true avulsion from the spinal cord, which is an injury to the central nervous system. Until recently, this distinction could be made only by inspection of the cord or histological examination of the tips of avulsed rootlets, but it is likely that improvements in MRI techniques will make the diagnosis possible.

An accurate history and physical examination allow a neurological diagnosis in most cases. The relative violence of the injury and estimate of the force applied to the limb are particularly significant. The characteristic pain from a preganglionic injury starts on the first day in about $50 \%$ of cases; the patients describe a constant crushing or burning pain in the hand with superimposed 'lightning shocks' shooting down the limb. Linear abrasions from the neck to the shoulder, swelling in the posterior triangle and vascular injury all suggest that a violent traction force has been applied.

The extent of nerve damage is easily ascertained by those who have studied the MRC memorandum Aids to examination of the peripheral nervous system (1976); all surgeons treating injuries should be familiar with this work. Determination of the level of the lesion, whether it is intradural or a postganglionic rupture, is more difficult, but complete sympathetic paralysis is a sign of rupture. Preganglionic injury of the upper three roots of the plexus is suggested by loss of sensation above the clavicle, with paralysis of the ipsilateral hemidiaphragm, serratus anterior and trapezius; a Bernard-Horner sign indicates a similar injury to the lower two roots. A strongly positive Tinel sign suggests a postganglionic rupture. Percussion of the posterior triangle of the neck causes the patient to feel pins and needles radiating to the elbow when the fifth cervical nerve has been so damaged; if these sensations extend to the thumb and index finger, then the sixth cervical nerve has been injured. Plain radiographs of the neck and the chest are always useful. Tilting of the cervical spine away from the side of injury is suggestive of complete intradural injury; fractures of the transverse process of $\mathrm{C} 7$ or of the first rib may indicate intradural injury of the lower two roots.
Variation in the anatomy of the brachial plexus is a major pitfall in clinical diagnosis. It is not uncommon to find the digital extensors innervated by the first thoracic nerve; conversely, many patients with intact $\mathrm{C} 8$ and $\mathrm{T} 1$ have paralysis of all extensor muscles. 'Pre' and 'post' fixation of the plexus is rarely significant.

Special investigations. Physiological diagnosis is based on Bonney's finding that afferent axons remain myelinated if they are still in continuity with the dorsal root ganglion. If intradermal histamine induces a flare in anaesthetic skin then the spinal nerve supplying that skin has been avulsed from the spinal cord. If a sensory action potential can be recorded from the stimulation of an anaesthetic index finger then the sixth cervical nerve has been damaged in this way. These investigations are useful only after Wallerian degeneration has taken place, at least three weeks after injury. Early myelography, within a few days of injury, may be difficult to interpret when there has been a tear of the dura, but a good-quality myelogram is extremely useful after about seven days and even better when combined with CT. The demonstration of evoked potentials from scalp electrodes by the stimulation of exposed spinal nerves excludes avulsion. Kline (1989) has shown the value of intraoperative nerve action potentials in the diagnosis of lesions in continuity, notably those caused by gunshot injuries.

MRI is valuable in demonstrating lesions of the spinal cord and of injury within the posterior triangle. It can distinguish between denervated, partially denervated and innervated muscle (Fleckenstein et al 1993). Francel et al (1995) have extended its use to the diagnosis of birth lesions of the brachial plexus.

\section{OPERATION}

The patient is placed in a half-sitting position. The injured limb and the posterior triangle of the neck beyond the midline are prepared. The lower limbs are prepared to allow access to the sural nerves and long saphenous veins. The use of neuromuscular blocking agents is avoided to permit the use of a nerve stimulator.

The choice of incisions is dictated by need; more detailed descriptions have been given elsewhere (Birch 1991). A transverse supraclavicular incision is adequate for most cases. The exposure described by Fiolle and Delmas (1921) extends the transverse wound into the deltopectoral groove with release of the pectoralis muscles and osteotomy of the clavicle, and is best for access between the second part of the subclavian artery and the distal axillary artery. The transclavicular approach of Birch, Bonney and Marshall (1990) is valuable for difficult cases of injury to the lower trunk of the brachial plexus and is occasionally indicated for exposure of the first part of the subclavian artery and vein and the proximal part of the vertebral artery. Access for control of more proximal bleeding requires a sternotomy. 
After exposure and control of the great vessels any associated fractures should be stabilised. Internal fixation by rod or nail is best for the humerus; external fixation may be indicated for grossly contaminated wounds from missiles. Arterial injuries are repaired by reversed vein grafts. As Barros d'Sa (1992) has emphasised, repair of any major injury to a vein is essential. Prosthetic vascular grafts are not suitable for these cases; they do not adapt to changes in posture of the limb and excite such dense fibrosis that they may prevent later nerve repair.

Conventional nerve grafting is the mainstay for the repair of ruptured nerves and it is usually necessary even in cleancut wounds. The free, vascularised, ulnar nerve graft of Jamieson and Eames (1980) may be indicated when the prognosis for recovery through the ulnar nerve is hopeless, but early enthusiasm for this technique has now diminished and it should be used only in special cases in which there is a badly-scarred bed or a very long gap between stumps (Birch et al 1988).

Nerve transfer. The transfer of an uninjured nerve to the distal stump of an injured nerve is not a new idea; some techniques developed in the last 20 years have proved useful. These include the accessory to suprascapular transfer of Allieu (1989) which was recommended to us by Professor Laurent Sedel (personal communication 1990), but it is essential to preserve the branches to the upper fibres of the trapezius. Intercostal nerves are useful for transfer to the long thoracic nerve, the circumflex nerve, the lateral cord, the musculocutaneous nerve and the lateral head of the median nerve. The transfer of a bundle of the intact ulnar nerve to the nerve to biceps (Oberlin 1994) seems particularly promising. The radical proposal of using part of the uninjured contralateral seventh cervical nerve to reinnervate the damaged upper limb was made by Chen and $\mathrm{Gu}$ (1994). Their results are promising although few European surgeons seem willing to risk damage to the function of a normal upper limb.

Open wounds. We find the distinction between tidy and untidy wounds introduced by Australian plastic surgeons very useful (Rank, Wakefield and Hueston 1973). A 'tidy' wound allows primary repair of all structures; for an 'untidy' wound the surgeon is limited to wound excision, probably repeated, to stabilisation of the skeleton and to restoration of the circulation with delayed wound closure.

Regrettably, a proportion of the tidy wounds referred to us has been caused by surgeons who had inadvertently resected portions of the brachial plexus during an operation for lymph-node biopsy. In one case the whole of the brachial plexus had been excised for a benign schwannoma. The incidence of such injuries appears to be increasing, and many have been caused in day-surgery units. No other injury to peripheral nerves has a stronger indication for urgent repair and few repairs have such worthwhile results.

The early and competent repair of clean stab wounds involving C5 to C7 can confidently be expected to yield return of function to nearly normal levels. Under these circumstances useful function can be anticipated in the hand after accurate repair of C8 and T1. Dunkerton and Boome (1988) summarised their experience with $64 \mathrm{stab}$ wounds and recommended grafting even in early cases. They also described the effect of a false aneurysm on conduction in adjacent nerve trunks, noting that deep pressure sense was maintained, and showed that careful epineurotomy was valuable after vascular injury.

The treatment of the untidy (contaminated) wound requires wholly different consideration. The principles of treatment, as defined by Robert Jones, were implemented by surgeons in the First World War. These included debridement (in its proper sense, to unbridle and decompress), wound excision, and delayed primary closure. Close-range gunshot or high-velocity missile injuries cause extensive tissue damage and it may be impossible to establish what is viable from what should be excised at the first operation. The wound is never primarily closed. The correct course of action includes stabilisation of the skeleton (best achieved for the humerus by external fixator), restoration of the circulation by a reversed vein graft tunnelled away from the wound, and adequate wound excision. At 48 hours, a second examination of the wound should lead to further excision. Dead bone must be removed and the wound may then be ready for closure, preferably by myocutaneous flap. In such cases nerves should be repaired only after all dead tissue has been excised and the risk of sepsis has been overcome.

Delorme (1915), Inspector General of the Armies of France, described a method of dealing with shell or bullet wounds of nerves to which little can be added. He proposed that surrounding scar tissue be removed until healthy tissue is reached, that the injured segment of the nerve should be resected until healthy stumps are visible, and that tension should be avoided by mobilising the nerve and immobilising the joints. He was so roundly criticised by the great and good of those days that one is tempted to ask whether Schiller's aphorism passed through his mind "Mit der Dummheit kämpfen Götter selbst vergebens". Tinel (1917) supported Delorme and commended the use of nerve grafts for long defects. The International Red Cross classification of war wounds of limbs (Coupland 1993) should be used more widely in civilian practice, particularly for the immensely destructive close-range gunshot wound. The appalling effects of this have been described by Cooper and Ryan (1990), Stewart and Kinninmonth (1993) and Stewart and Birch (1996). Stewart has proposed three types of missile injury: from bullets, fragments, or blast. Of the three the blast injury is the worst.

Kline (1989) described a series of 141 gunshot wounds treated over 18 years. Urgent vascular repair was necessary in 30 of the 90 operated cases; in eight thoracotomy was required and operation was necessary in six more for expanding false aneurysms. An important contribution from this work is the analysis of lesions in continuity, using 
intraoperative recordings of nerve action potentials. Kline observed 166 such lesions and was able to record an action potential across 48 of them; all 48 recovered. When no action potential was found to traverse the lesion, Kline resected and grafted. Histological examination of the resected specimens showed unfavourable and "neurotmetic or Sunderland grade 4 appearance". Kline's paper and that of Dunkerton and Boome (1988) are important and will repay careful reading.

Closed supraclavicular lesions. These are the most common injuries to the brachial plexus, but despite some improvement in results for injuries of $\mathrm{C} 5$ to $\mathrm{C} 7$, the general outcome remains disappointing. The restoration of hand function after a complete lesion in an adult cannot be expected. It is convenient to consider four groups:

Complete C4 to $T 1$ (5\%). These most severe injuries are irreparable. The limb is virtually torn from the trunk, and the subclavian artery is ruptured. Sensory loss extends above the clavicle, there is paralysis of the hemidiaphragm, and the trapezius is weak or paralysed.

Avulsion C5 to T1 (15\%). Conventional treatment is by nerve transfer to reinnervate the long thoracic and suprascapular nerves and the lateral cord. The aims of treatment include stability of the scapula and shoulder, active flexion of the elbow, some protective sensation in the median territory of the hand, and relief of pain. Tsuyama's group started using intercostal nerve transfer in 1965 and have described their results in 179 cases (Nagano et al 1989). Functional flexion of the elbow was gained in $80 \%$ of cases. These are impressive results, especially as the most important cause of failure was delay. European surgeons have not been able to match these results, but intercostal transfer is recognised as a valuable addition to the treatment of the otherwise hopeless case. The relief of pain is a very important bonus in a number of patients.

Rupture C5 to C6 (C7), avulsion (C7) C8/T1 (about 30\%). Grafting is combined with nerve transfer, and a vascularised ulnar nerve graft is occasionally indicated. If the operation is performed within weeks of injury, about $70 \%$ of patients regain useful function at the shoulder and arm, with stability at the wrist, recovery of some sensation and relief of pain.

Rupture or avulsion $C 5$ to C6 (C7), with an intact (C7) C8 to $T 1$ (about 35\%). This is the most favourable group: the patient still has some hand function. Over the last 20 years, this group has given the most striking improvement in results. The combination of grafting and nerve transfer can give useful improvement in function at the shoulder, elbow and hand in most patients, but it is essential that the operation is performed early. If the spinal nerves have been avulsed, possible transfers include reinnervation of the long thoracic nerve by the nerve to levator scapulae or intercostal nerves, transfer of the accessory to the suprascapular nerve, transfer from the ulnar nerve to the nerve to biceps, and the use of intercostal nerves to reinnervate either the lateral head of the median nerve or the circumflex nerve.
Early flexor-to-extensor tendon transfer should be advised in patients with wrist drop.

Closed infraclavicular lesions. These injuries form between $25 \%$ and $33 \%$ of large series of brachial plexus lesions. The level is between the clavicle and the inferior margin of pectoralis major. The incidence of vascular injury is about $25 \%$, and there are usually associated fractures or fracture dislocations of the proximal humerus and shoulder girdle. The distinction between infraclavicular lesions (peripheral nerves) and supraclavicular lesions (spinal nerves) is somewhat artificial. A knife or a missile does not respect anatomical boundaries, and even in closed traction injuries some $15 \%$ have two-level lesions usually presenting as preganglionic injuries of $\mathrm{C} 8$ and $\mathrm{T} 1$ with rupture of the lateral and posterior cords.

Cavanagh, Bonney and Birch (1987) reviewed 130 nerve repairs for closed infraclavicular lesions. Their most significant finding was that nerves repaired within 14 days of injury had much better results than those repaired later.

Rehabilitation. Vigorous rehabilitation aimed at a return to normal life is essential for both psychological and physical well-being. This is the responsibility of the surgeon in charge of the case. Close supervision is necessary; judicious and well-timed secondary operations for reconstruction can assist progress. The work of the multidisciplinary residential rehabilitation unit for patients with severe injuries of peripheral nerves at the Royal National Orthopaedic Hospital has been reviewed by Wynn Parry, Frampton and Monteith (1987).

Pain. Loss of a limb is bad enough - severe pain persisting in a useless arm is even worse. Nearly all patients with preganglionic injury of a spinal nerve experience pain. It is worst in complete avulsion lesions and appears to be more severe after avulsion of C8 and T1 than when C5 and C6 are so injured. The patient's description of the pain is diagnostic of the lesion. At first there is a constant crushing or burning pain in the otherwise anaesthetic hand. This is de-afferentation pain. Superimposed on this, lightning-like stabs of pain course down the whole of the upper limb. These are due to convulsive abnormal activity in the damaged dorsal horn of the spinal cord and are associated with true avulsion. The most important methods of treatment are mental distraction and re-innervation of the limb. Wynn Parry et al (1987) studied several hundred patients for up to 30 years and emphasised the effectiveness of distracting attention from the pain by involvement in work or study. This is a strong argument in favour of their policy for rehabilitation.

Berman et al (1996) found that pain was relieved by late intercostal transfer in 16 of their 19 patients; their study confirmed earlier impressions that successful re-innervation often relieves pain (Fig. 1).

Some patients remain demoralised by extreme pain after all modes of treatment have been exhausted. For them, a direct approach to the central nervous system is the last resort, but the interruption of spinal tracts in patients with 


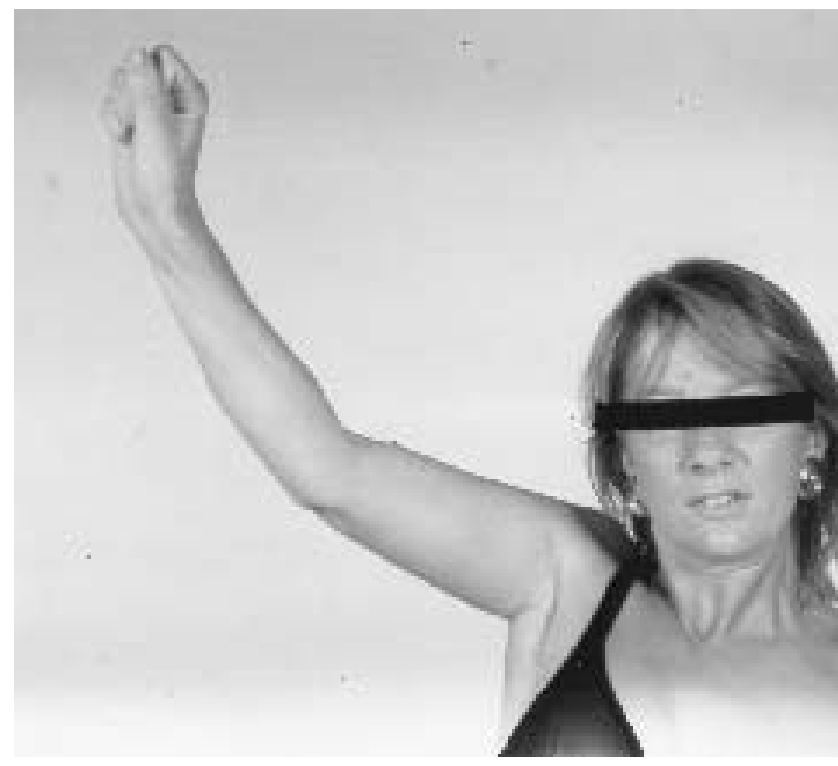

Fig. 1

A 28-year-old woman sustained a preganglionic injury of the C5, C6 and C7 nerves. Transfer of accessory to suprascapular nerves, and of intercostal T3, T5, T6 to musculocutaneous and the lateral root of median nerves restored useful shoulder control and elbow flexion. Her pain, which had been severe, disappeared with the return of muscle function at nine months.

chronic pain has had poor results. Thomas (1988) reviewed his experience with thermocoagulation in the dorsal-root entry zone (DREZ lesion) in over 50 patients. Pain was improved in two-thirds, but $10 \%$ had a significant and lasting neural deficit affecting the ipsilateral cervical cord. This operation should be reserved for those in intolerable pain after all other treatments have been tried. The complications are severe, and few young patients will wish to proceed once the risks have been properly explained.

The reintroduction of dorsal-column stimulation offers promise for these patients with less hazard. Tai, personal communication, has achieved lasting relief in over twothirds of his patients with few complications.

\section{CONCLUSIONS}

The important advances of the last 30 years include: refinement of diagnosis; re-learning and re-application of the

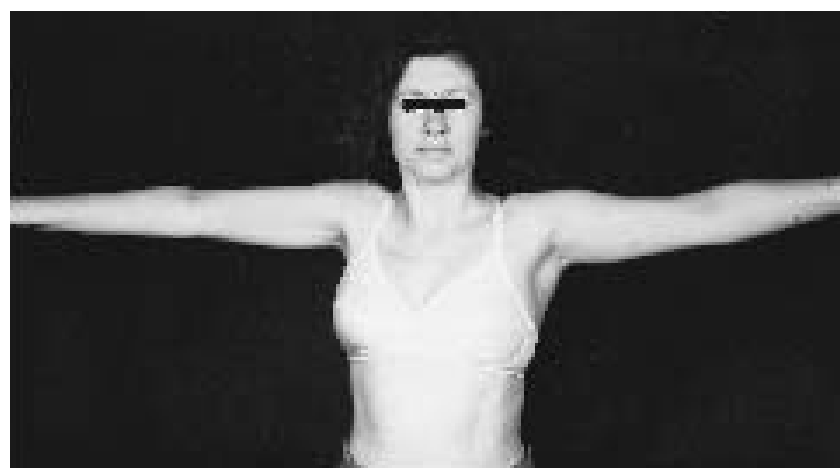

Fig. 2

A 26-year-old woman suffered rupture of C5 nerve with avulsion of C6 and $\mathrm{C} 7$. The $\mathrm{C} 8$ and $\mathrm{T} 1$ nerves were intact. Early repair, by graft and transfer, restored a useful and painfree upper limb at 24 months.

principles of the treatment of wounds and vascular lesions; improved methods of nerve repair and transfer; and, most importantly, a policy of urgent exploration and repair. Good functional recovery can reasonably be expected in patients with either pre- or postganglionic damage to the fifth, sixth and seventh cervical nerves, and intact eighth cervical and first thoracic nerves (Fig. 2). If surgeons renounce the harmful policy of procrastination most patients can achieve restoration of thoracoscapular control, glenohumeral control, elbow flexion and wrist extension, with normal sensation within the median territory of the hand and the relief of pain.

The outlook for patients with complete lesions, however, is much more gloomy. For these patients, who are in the majority, only direct replantation of avulsed nerves into the spinal cord offers any hope. Bonney repaired some avulsed dorsal rootlets in 1976, but there was no recovery. In 1980 Jamieson and Eames reported functional recovery after the repair of ventral roots in dogs. Carlstedt et al (1993) greatly extended this early experimental work and in 1995 Carlstedt and his team were able to prove that it worked in man. This is a fundamental advance; together with new knowledge about the roles of neurotrophins in preserving cell bodies within the spinal cord and enhancing regeneration (Anand et al 1994), there is now a real prospect of mitigating the worst of all injuries to peripheral nerves.

\section{REFERENCES}

Allieu Y. Les neurotisations par le nerf spinal dans les avulsions du plexus brachial de l'adulte. In: Alnot JY, Narakas A, eds. Les paralysies du plexus brachiale. Monographies du Groupe d'Étude de la Main. Paris: Expansion Scientifique Française, 1989:173-9.

Anand P, Birch R, Parrett A, et al. Nerve growth factor and ciliary neurotrophic factor in human peripheral nerves after injury. Ann Neurol 1994;36:319A.

Barros d'SA. Arterial injuries. In: Eastcott HHG, ed. Arterial surgery. 3rd ed. Edinburgh, London etc: Churchill Livingstone, 1992:355-414.

Berman J, Anand P, Chen L, Taggart M, Birch R. Pain relief from preganglionic injury to the brachial plexus by late intercostal transfer. J Bone Joint Surg [Br] 1996;78-B:759-60.

Berthold C-H, Carlstedt T, Corneliuson O. The central-peripheral transition zone. In: Dyck PJ, Thomas PK, eds. Peripheral neuropathy. 3rd ed. Philadelphia, WB Saunders, 1993;1:73-91.

Birch R. Major neurovascular bundles. In: Colton CL, Hall AJ, eds Atlas of orthopaedic surgical approaches. Oxford, etc: Butterworth-Heinemann, 1991:120-33.

Birch R, Bonney G, Marshall RW. A surgical approach to the cervicothoracic spine. J Bone Joint Surg [Br] 1990;72-B:904-7.

Birch R, Dunkerton M, Bonney G, Jamieson AM. Experience with the free vascularised ulnar nerve graft in repair of supraclavicular lesions of the brachial plexus. Clin Orthop 1988;237:96-104. 
Bonney G. The value of axon responses in determining site of the lesion in traction injuries of brachial plexus. Brain 1954;77:588-609.

Bonney G. Prognosis in traction lesions of the brachial plexus. $J$ Bone Joint Surg [Br] 1959;41-B:4-35.

Bonney G, Gilliatt RW. Sensory nerve conduction after traction injuries of the brachial plexus. Proc R Soc Med 1958;51:365-7.

Brooks D. The place of nerve grafting in orthopaedic surgery. $J$ Bone Joint Surg [Am] 1955;37-A:299-305;326.

Carlstedt TP, Hallin RG, Hedstrom KG, Nilsson-Remahl IA. Functional recovery in primates with brachial plexus injury after spinal cord implantation of avulsed ventral roots. J Neurol Neurosurg Psychiatry 1993;56:649-54.

Carlstedt T, Grane P, Hallin RG, Noren G. Return of function after spinal cord implantation of avulsed spinal nerve roots Lancet 1995;346:1323-5.

Cavanagh SP, Bonney G, Birch R. The infraclavicular brachial plexus: the case for primary repair. J Bone Joint Surg [Br] 1987;69-B:489.

Celli L, Rovesta C, Electrophysiologic intraoperative evaluations of the damaged root in traction of the brachial plexus. In: Terzis JK, ed. Microreconstruction of nerve injuries. Philadelphia, etc: WB Saunders, 1987:473-82.

Chen L, Gu YD. An experimental study of contralateral C7 root transfer with vascularised nerve graft to treat brachial plexus root avulsion. $J$ Hand Surg 1994;19-B:60-6.

Cooper DJ, Ryan JM. Interaction of penetrating missiles with tissues: some common misapprehensions and implications for wound management. Br J Surg 1990;77:606-10.

Coupland RM. War wounds of limbs. Oxford, etc: Butterworth-Heinneman, 1993.

Davies ER, Sutton D, Bligh AS. Myelography in brachial plexus injury. Br J Radiol 1966;39:362-71.

DeBakey ME, Simeone FA. Acute battle-incurred arterial injuries World War II. In: Medical Department US Army. Vascular surgery in World War II. US Government Printing Office, 1955:60-148.

Delorme E. The treatment of gunshot wounds of the nerves. Brit Med J 1915:853-5.

Dunkerton MC, Boome RS. Stab wounds involving the brachial plexus. J Bone Joint Surg [Br] 1988;70-B:566-70.

Fiolle J, Delmas J. The surgical exposure of the deep-seated blood vessels. London: W. Heinemann, 1921:61-7.

Flaubert AC. Mémoire sur plusiers cas de luxations dans les efforts pour la réduction ont été suivis d'accidents graves. Répertoire générale d'anatomie et de physiologie pathologique 1827;3:55-69.

Fleckenstein J, Watumull D, Conner KE, et al. Denervated human skeletal muscle MR imaging evaluation. Radiology 1993;187:213-8.

Francel PC, Koby M, Park TS, et al. Fast-spin echo magnetic resonance imaging for radiological assessment for neonatal brachial plexus injury. J Neurosurg 1995;83:461-6.

Frazier CH, Skillern PG. Supraclavicular subcutaneous lesions of the brachial plexus not associated with skeletal injuries. J Am Med Assoc 1911;57:1957-63.
Jamieson AM, Eames RA. Reimplantation of avulsed brachial plexus roots: an experimental study in dogs. Int J Microsurgery 1980; 2:75-80.

Kline DG. Civilian gunshot wounds to the brachial plexus. J Neurosurg 1989;70:166-74.

Landi A, Copeland SA, Wynn Parry CB, Jones SJ. The role of somatosensory evoked potentials and nerve conduction studies in the surgical management of brachial plexus injuries. J Bone Joint Surg [Br] 1980;62-B:492-6.

Marshall RW, de Silva RD. Computerised axial tomography in traction injuries of the brachial plexus. J Bone Joint Surg [Br] 1986;68-B 734-8.

Medical Research Council. Peripheral nerve injuries. Medical Research Council Special Report Series No. 282, London: HMSO, 1954.

Medical Research Council. Aids to examination of the peripheral nervous system. Memorandum No. 45, London. HMSO, 1976.

Nagano A, Tsuyama N, Ochiai N, Hara T, Takahashi M. Direct nerve crossing with the intercostal nerve to treat avulsion injuries of the brachial plexus. J Hand Surg 1989;14-A:980-5.

Oberlin C. Neurotisation of nerve to biceps muscle by means of fascicles from ulnar nerve. XI Symposium on Brachial Plexus Surgery. In: Bonnard C, ed: Clinique de Langeraie 1994;76-7.

Rank BK, Wakefield AR, Hueston JT. Surgery of repair as applied to hand injuries. 4th ed. Edinburgh, etc: Churchill Livingstone, 1973.

Seddon HJ. Nerve grafting: Fourth Watson-Jones lecture of the Royal College of Surgeons of England. J Bone Joint Surg [Br] 1963; 45-B:447-61.

Stewart MPM, Kinnimonth A. Shotgun wounds of the limbs. Injury 1993;24:667-70.

Stewart MPM, Birch R. Penetrating missile injuries of the brachial plexus. J Bone Joint Surg [Br] 1996;Suppl II \& III:165-6..

Strange FG, StC. An operation for nerve pedicle grafting: preliminary communication. Br J Surg 1947;34:423-5.

Sugioka H, Nagano A. Électrodiagnostic dans l'évaluation des lésions par élongation du plexus brachial. In: Alnot J-Y, Narakas A, eds. Les paralysies du plexus brachial. Monographies du Groupe d'Etude de la Main, 15. Paris: Expansion Scientifique Française, 1989:123-9.

Thorburn W. Secondary suture of the brachial plexus. Brit Med J 1900;I:1073-5.

Thomas DGT. Dorsal root entry zone thermocoagulation. In: Schmidek $\mathrm{HH}$, Sureet WH, eds. Operative neurosurgical techniques. 2nd ed. Philadelphia: WB Saunders, 1988:1169-76.

Tinel J. Nerve wounds. Revised and edited by Joll CA. Ballière Tindall and Cox, London, 1917.

Wynn Parry CB, Frampton V, Monteith A. Rehabilitation of patients following traction lesion of the brachial plexus. In: Terzis JK, ed Microreconstruction of nerve injuries. Philadelphia: WB Saunders, 1987:483-95

Yeoman PM. Cervical myelography in traction injuries of the brachial plexus. J Bone Joint Surg [Br] 1958;50-B:253-60.

Young JZ, Medawar PB. Fibrin suture of peripheral nerves. Lancet 1940;II:126-8. 